\title{
First Confirmed Visit
}

National Cancer Institute

\section{Source}

National Cancer Institute. First Confirmed Visit. NCI Thesaurus. Code C159705.

An indication of the first visit during which a particular event or status was confirmed. 